\title{
The influence of hashed fingerprints density on the machine learning methods performance
}

\author{
Sabina Smusz ${ }^{1,2^{*}}$, Rafał Kurczab ${ }^{1}$, Andrzej J Bojarski ${ }^{1}$ \\ From 8th German Conference on Chemoinformatics: 26 CIC-Workshop \\ Goslar, Germany. 11-13 November 2012
}

Computational techniques have become a vital part of today's drug discovery campaigns. Among a wide range of tools applied in this process, machine learning methods can be distinguished. They are used for instance in virtual screening (VS), where its role is to identify potentially active compounds out of large libraries of structures [1].

In order to enable the application of various learning algorithms in VS tasks, an appropriate representation of molecules is needed. One of the solutions comes from the hashed fingerprints, encoding the information about the structure in a form of a bit string [2].

Both length and density (the percentage of 1's) can be modified during hashed fingerprint generation, which (as it was already proved) influence the similarity searching process [3]. The aim of our study was to examine the impact of such fingerprint density on the performance of machine learning methods. A series of bit strings with different density values and of various lengths was generated by means of the RDKit software [4]. They were tested in classification tests of $5-\mathrm{HT}_{1 \mathrm{~A}}$ ligands, with the use of a set of algorithms (Naïve Bayes, SMO, Ibk, Decorate, Hyperpipes, J48 and Random Forest), in order to determine an optimal values of the variables for machine learning experiments.

\section{Acknowledgements}

The study was supported by a grant PRELUDIUM 2011/03/N/NZ2/02478 financed by the National Science Centre.

\section{Author details}

'Department of Medicinal Chemistry, Institute of Pharmacology Polish Academy of Sciences, Kraków, 31-343, Poland. 'Faculty of Chemistry, Jagiellonian University, Kraków, 30-060, Poland.

Published: 22 March 2013

\footnotetext{
* Correspondence: smusz@if-pan.krakow.pl

'Department of Medicinal Chemistry, Institute of Pharmacology Polish

Academy of Sciences, Kraków, 31-343, Poland

Full list of author information is available at the end of the article
}

\section{References}

1. Geppert H, Vogt M, Bajorath J: Current Trends in Ligand-Based Virtual Screening: Molecular Representations, Data Mining Methods, New Application Areas, and Performance Evaluation. J Chem Inf Model 2010, 50:205-216.

2. Rijnbeek $M$, Steinbeck $C$ : OrChem - An open source chemistry search engine for Oracle ${ }^{\oplus}$. J Cheminf 2009, 1:17.

3. Wang Y, Bajorath J: Balancing the Influence of Molecular Complexity on Fingerprint Similarity Searching. J Chem Inf Model 2008, 48:75-84.

4. RDKit: Open-source cheminformatics. [http://www.rdkit.org].

\section{doi:10.1186/1758-2946-5-S1-P25}

Cite this article as: Smusz et al:: The influence of hashed fingerprints density on the machine learning methods performance. Journal of Cheminformatics 2013 5(Suppl 1):P25.

\section{Publish with ChemistryCentral and every scientist can read your work free of charge \\ "Open access provides opportunities to our colleagues in other parts of the globe, by allowing anyone to view the content free of charge." \\ W. Jeffery Hurst, The Hershey Company. \\ - available free of charge to the entire scientific community \\ - peer reviewed and published immediately upon acceptance \\ - cited in PubMed and archived on PubMed Central \\ - yours - you keep the copyright \\ Submit your manuscript here: \\ http://www.chemistrycentral.com/manuscript/

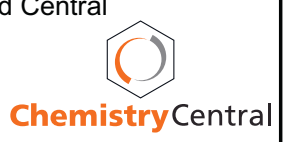

